NASA/TM-2001-210705

\title{
Effects of Gravity on Cocurrent Two-Phase Gas-Liquid Flows Through Packed Columns
}

Brian J. Motil

Glenn Research Center, Cleveland, Ohio

Vemuri Balakotaiah

University of Houston, Houston, Texas

Yasuhiro Kamotani

Case Western Reserve University, Cleveland, Ohio

Prepared for the 39th Aerospace Sciences Meeting and Exhibit sponsored by the American Institute of Aeronautics and Astronautics Reno, Nevada, January 8-11, 2001

National Aeronautics and Space Administration

Glenn Research Center 
This report contains preliminary

findings, subject to revision as analysis proceeds.

Available from

NASA Center for Aerospace Information 7121 Standard Drive

Hanover, MD 21076

Price Code: A03
National Technical Information Service 5285 Port Royal Road Springfield, VA 22100

Price Code: A03

Available electronically at http://gltrs.grc.nasa.gov/GLTRS 


\title{
EFFECTS OF GRAVITY ON COCURRENT TWO-PHASE GAS-LIQUID FLOWS THROUGH PACKED COLUMNS
}

\author{
Brian J. Motil \\ National Aeronautics and Space Administration \\ Glenn Research Center \\ 21000 Brookpark Road \\ Cleveland, Ohio 44135 \\ Vemuri Balakotaiah \\ University of Houston \\ 4800 Calhoun Road \\ Houston, Texas 77204 \\ Yasuhiro Kamotani \\ Case Western Reserve University \\ 10900 Euclid Avenue \\ Cleveland. Ohio 44106
}

\begin{abstract}
$\underline{\text { Abstract }}$
This work presents the experimental results of research on the influence of gravity on flow pattern transitions, pressure drop and flow characteristics for cocurrent gasliquid two-phase flow through packed columns. The flow pattern transition data indicates that the pulse flow regime exists over a wider range of gas and liquid flow rates under reduced gravity conditions compared to normal gravity cocurrent down-flow. This is illustrated by comparing the flow regime transitions found in reduced gravity with the transitions predicted by Talmor. ${ }^{1}$ Next, the effect of gravity on the total pressure drop in a packed column is shown to depend on the flow regime. The difference is roughly equivalent to the liquid static head for bubbly flow but begins to decrease at the onset of pulse flow. As the spray flow regime is approached by increasing the gas to liquid ratio, the effect of gravity on pressure drop becomes negligible. Finally, gravity tends to suppress the amplitude of each pressure pulse. An example of this phenomenon is presented.
\end{abstract}

\section{$\underline{\text { Introduction }}$}

Long duration manned space activities will depend on the development of regenerative life support systems based on physicochemical and/or biological technologies. NASA and the NRC have identified through a workshop ${ }^{2}$ and a commissioned study ${ }^{3}$ that multiphase processing of in-situ resources must be made possible under conditions ranging from zero to partial gravities (e.g., Mars, $0.38 \mathrm{~g}$, Lunar $0.17 \mathrm{~g}$ ), if NASA's goals of Human Exploration and Development of Space (HEDS) are to be achieved. One of the "enabling" unit operations critical to many of these systems is the packed (fixed) bed reactor with co-current flow of gas and liquid.

In the typical operation of the packed bed reactor, gas and liquid flow simultaneously through a fixed bed of solid particles. The particles can be various shapes and sizes and serve to force the two fluid phases through the narrow channels connecting the interstitial voids. This configuration provides for the intimate contact needed between the phases to sustain chemical or biological reactions. The packing may also serve as either a catalytic site or as a surface for growing biological material. NASA has flown two of these systems in a microgravity environment with limited success. In both systems, it was assumed the effects of a weightless environment on the hydrodynamics were predictable (even though prior to this study no experimental data existed) and attention was focused on mass transfer. 
The Volatile Removal Assembly Flight Experiment ${ }^{t}$ (VRAFE) flew on STS-89 and STS-96. This experiment involved a high temperature catalytic oxidation process as a final treatment for recycled water. A loss of chemical performance was reported along with increased gas inclusion. The other system attempted by NASA was a biological reactor for the primary treatment of wastewater and was flown on NASA's KC-135 aircraft. The packed bed reactor approach was abandoned after it was recognized that hydrodynamic and phase distribution differences in a weightless environment prevented the reactor from functioning as designed.

The purpose of this study was to gain insight into the specific effects a reduced and high gravity environment has on such gas-liquid fixed bed reactor hydrodynamic parameters as flow patterns, phase distribution and pressure drop. We refer to the test section as a packed column or bed rather than a reactor since no mass transfer or reactions are taking place. This paper first presents a brief description of the flow regimes encountered on earth and how they can be mapped to include operation in reduced gravity. Pressure drop and liquid holdup comparisons are then discussed along with the effect of gravity on flow regime characteristics, such as pulse amplitude.

\section{Experimental}

\section{$\underline{\text { Test Apparatus }}$}

The Small Two-Phase Flow Experiment (STPFE) is an existing two-phase rig designed to fly on NASA's KC-135 aircraft. It was modified to accommodate the packed bed test section and instrumentation. An overview of the design is given by $\mathrm{Motil}^{5}$ et al. Figure 1 shows the test section which was a rectangular column with a cross section of $2.54 \times 5.08 \mathrm{~cm}$. The column was $60 \mathrm{~cm}$ long with 5 evenly spaced differential pressure transducers and was made from a clear polycarbonate material for viewing the phase

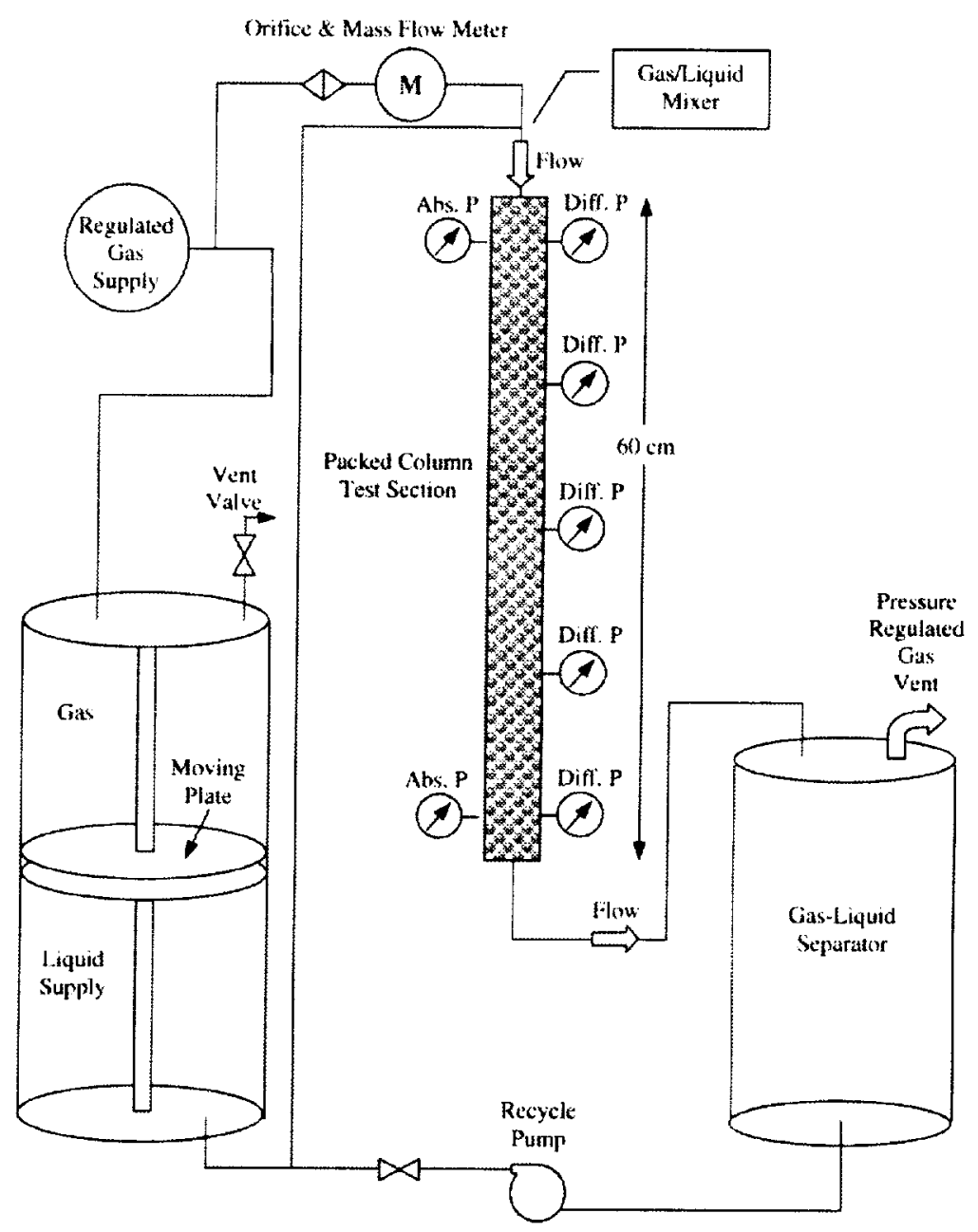

Figure 1.-Packed column test apparatus. 
distribution with a high speed SVHS video recorder. Absolute pressure transducers were also located opposite of the first and last differential transducers. Both phases were well mixed just prior to the inlet of the column. The column was randomly packed with identically sized spherical glass beads.

\section{Test Conditions}

The test conditions were designed to provide a wide range of flow parameters as well as include the major flow regimes. The gas phase was air and the liquid phase was a water-glycerin mixture. Variations of several orders-of-magnitude in the important dimensionless numbers were obtained by varying the packing size, gas and liquid flow rates, and the liquid viscosity (by changing the weight percent of glycerin). The ranges of dimensionless numbers, flow rates, fluid properties and packing diameters used in these experiments are given below:

$$
\begin{aligned}
& 0.18<\mathrm{Re}<100 \\
& 0.001<\mathrm{We}<1.0 \\
& 0.03<\mathrm{G}<0.8 \mathrm{~kg} /\left(\mathrm{s} \mathrm{m}^{2}\right) \\
& 3<\mathrm{L}<50 \mathrm{~kg} /\left(\mathrm{s} \mathrm{m}^{2}\right) \\
& 1<\mu_{\mathrm{L}}<20 \mathrm{cP} \\
& \sigma=68-72 \mathrm{dynes} / \mathrm{cm}^{2} \\
& \mathrm{D}_{\mathrm{p}}=2 \text { and } 5 \mathrm{~mm}
\end{aligned}
$$

where $G$ and $L$ are superficial mass velocities of the gas and liquid, $\mu_{L}$ is the liquid viscosity, $\sigma$ is the surface tension and $D_{p}$ is the packing diameter. The two-phase dimensionless groups (Reynolds and Weber numbers) are defined as:

$W e=\frac{D_{h}(L+G)^{2} v_{L G}}{\sigma}$

$\operatorname{Re}=\frac{D_{h}(L+G)}{\mu_{L G}}$

where

$$
v_{L G}=v_{L} \frac{L / G}{1+L / G}+v_{G} \frac{1}{1+L / G}
$$

$$
\begin{aligned}
& \mu_{L G}=\mu_{L} \frac{L / G}{1+L / G}+\mu_{G} \frac{1}{1+L / G} \\
& D_{h}=\frac{2 \varepsilon D}{2+3(1-\varepsilon)\left(D / D_{p}\right)}
\end{aligned}
$$

$\varepsilon$ is the packing bed void fraction, $v_{G}$ and $v_{L}$ are the respective gas and liquid specific volume, and $D$ is the hydraulic diameter of the empty bed.

Over 250 different test conditions were recorded in microgravity with a companion set of $1-\mathrm{g}$ tests to provide a direct comparison of the two environments.

\section{Flow Regimes}

\section{General Description}

It is generally accepted that for non-foaming systems, cocurrent gas-liquid downflow in packed beds on earth can be operated within four basic flow regimes. Weekman and Myers, ${ }^{6}$ Charpentier and Favier, ${ }^{7}$ and $\mathrm{Sato}^{8}$ et al. were among the first to provide detailed descriptions of each regime, but many others can be found in the literature. Two of the flow regimes can further be classified as "gas continuous" because the gas phase occupies most of the void space within the column. At both low gas and low liquid flow rates, trickle or channeled flow is observed. In this important flow regime, the liquid phase trickles down the packing. driven mainly by the draining force of gravity. The liquid forms a laminar film that frequently does not wet the entire packing surface and interaction between the phases is relatively low. As the gas flow is increased, the liquid film becomes turbulent and eventually the gas flow is strong enough to suspend droplets of liquid. This flow regime is generally called spray or mist flow. At higher liquid flow rates and relatively low gas flow, the continuous phase is now liquid and the gas phase is uniformly dispersed in small bubbles throughout the column. This regime is called bubbly flow. Finally, an interesting flow regime exists for a specific range of gas and liquid flow rates called the pulse flow regime. This flow regime can be observed as the liquid flow is increased beyond trickle flow until pulses (traveling waves) of liquid can be observed. The waves quickly grow until they span the entire cross section of the column. Pulses are first observed at the bottom of the column and their initial formation appears to move upward as the liquid flow is increased. A great deal of mixing between phases frequently makes this the desired flow regime for effective mass transfer despite the fact that the actual mechanism of pulse formation 
and the trickling to pulsing transition is still an active area of research. The transition to pulse flow may also occur from the liquid continuous bubbly flow regime by increasing the gas flow rate. While many $1-\mathrm{g}$ studies focused on the trickling to pulsing transition, very little work has been reported on the bubbly to pulse transition. Since the former transition does not exist in $0-\mathrm{g}$ and the latter exists in both $1-\mathrm{g}$ and $0-\mathrm{g}$ (as well as high or intermediate $g$ values), studying the influence of gravity on this transition is useful in understanding the role gravity forces have on all transition boundaries.

\section{Flow Maps}

Many attempts have been made to predict where the transitions between flow regimes will occur. Models based on hydrodynamic stability theory have been proposed as well as flow maps using dimensionless and even dimensional parameters. The variables influencing the flow pattern transitions are the gas and liquid densities, viscosities, and velocities. In addition, interfacial tension, gravitational acceleration and the packing and column diameters must be considered. These ten variables give rise to seven dimensionless groups. To make it possible to correlate experimental data, these are normally combined into two groups.

Figure 2 shows such a dimensionless map by Talmor ${ }^{1}$ based on prior work by Oshinowo and Charles. ${ }^{9}$ His objective was to create a generalized flow map in terms of some useful coordinates that can be scaled over several orders of magnitude. One of these coordinates, the Froude number, includes the effect of gravity. The Talmor map was tested using multiple experimental studies conducted in normal gravity for non-foaming systems including air-water/glycerin, $\mathrm{CO}_{2}$-Hexane, Freon-Silicon Oil, and Natl. Gas/CO $/ \mathrm{CO}_{2} /$ Lube Oil. The map is generally accepted with some noted limitations.

The basis for the map is that a driving-to-resistance force ratio can be developed for two-phase flow through a packed column similar to two-phase flow through an empty tube. The driving forces are inertia and gravity while the resistance forces are viscous and surface tension. By normalizing the inertia forces and using two-phase Froude, Weber and Reynolds numbers, Talmor derives the force ratio as:

$\frac{1+(1 / F r)}{W e+(1 / \mathrm{Re})}=\frac{\text { Inertia }+ \text { Gravity }}{\text { Interface }+ \text { Viscous }}$

where

$F r=\frac{\left[(L+G) v_{L G}\right]^{2}}{g D_{h}}$

This flow map can then be applied to a microgravity environment by neglecting the gravity force term.

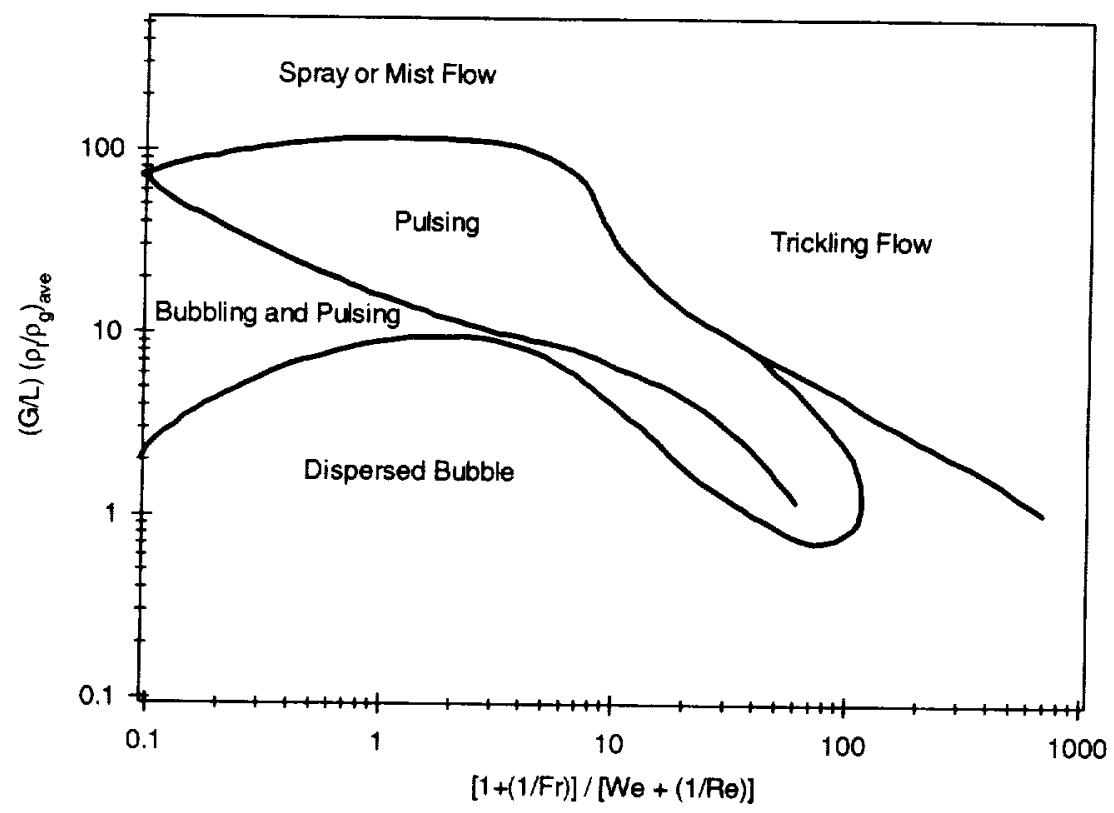

Figure 2.-Talmor flow regime map. 


\section{Flow Regimes in Reduced Gravity}

As mentioned earlier, the trickle flow regime exists because of the draining force of gravity. It seems reasonable, therefore, to expect trickle flow not to exist in microgravity. Instead, within the limitations of the experimental flow rates and 20 second microgravity durations, pulse or bubbly flow was observed at very low liquid and gas flow rates. Rather than draining, the liquid tends to spread in a radial (as well as axial) direction until a sufficient amount of liquid has plugged a cross sectional area. Depending on the gas flow rate, the plug will either continue to fill the column until it is the continuous phase or at slightly higher gas flow rates, it will become the start of a liquid pulse. The other extreme of the gas continuous flow is spray or mist flow, which occurs at a very high gas-to-liquid ratio. This flow regime was observed in only a few of our microgravity experiments, but as expected, the transition boundary and pressure drop were found to be nearly independent of gravity because this transition is dominated by inertia.

Based on the discussion above, our study focuses on the pulse and bubbly flow regimes. Figures 3 and 4 show typical pressure traces for bubbly and pulse flow respectively. Below each trace is the corresponding normalized frequency response, which is calculated using a Fast Fourier Transform (FFT) algorithm. The frequency response was considered along with a review of the high-speed video in determining the flow regime.
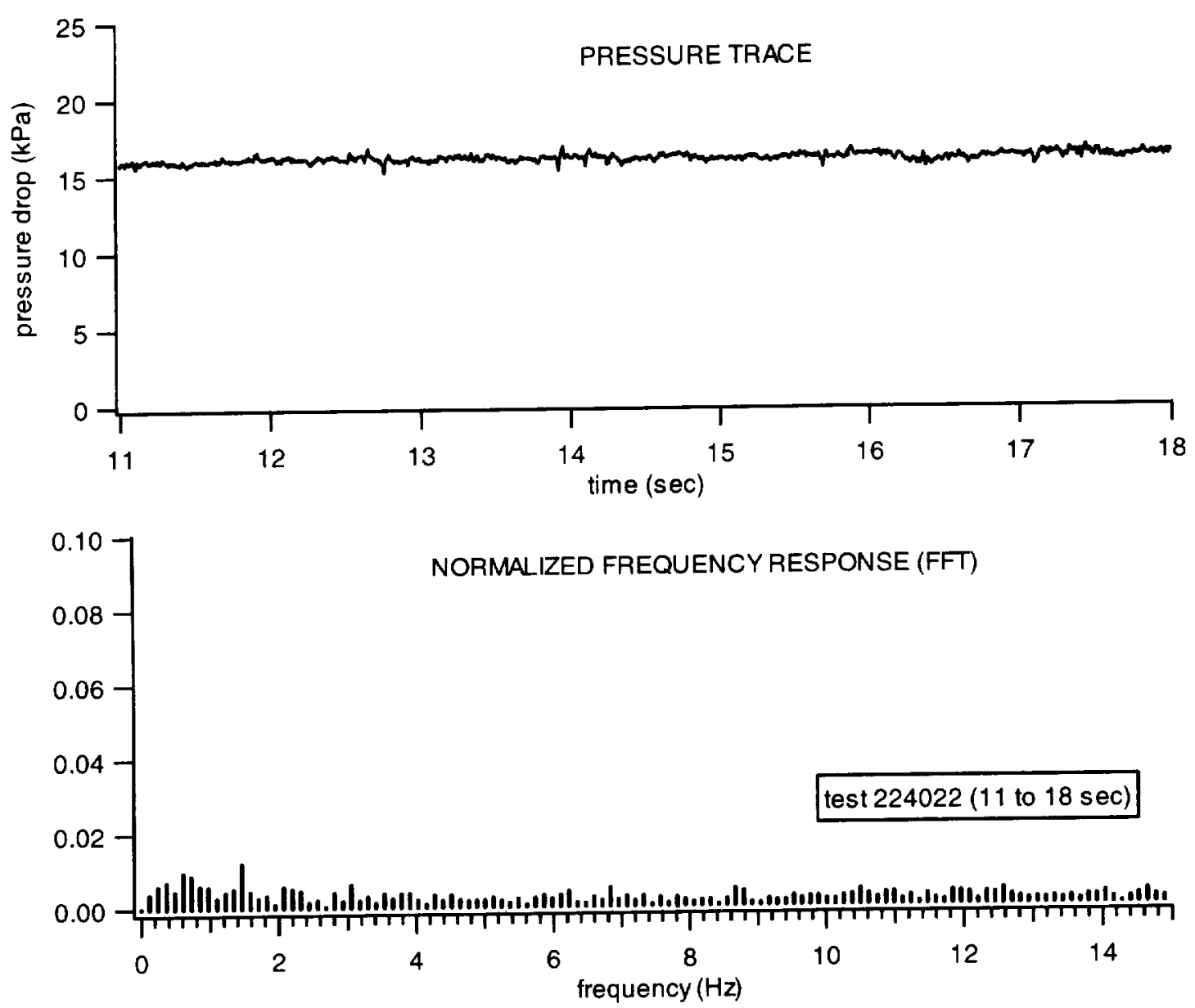

Figure 3.-Typical bubbly flow. 

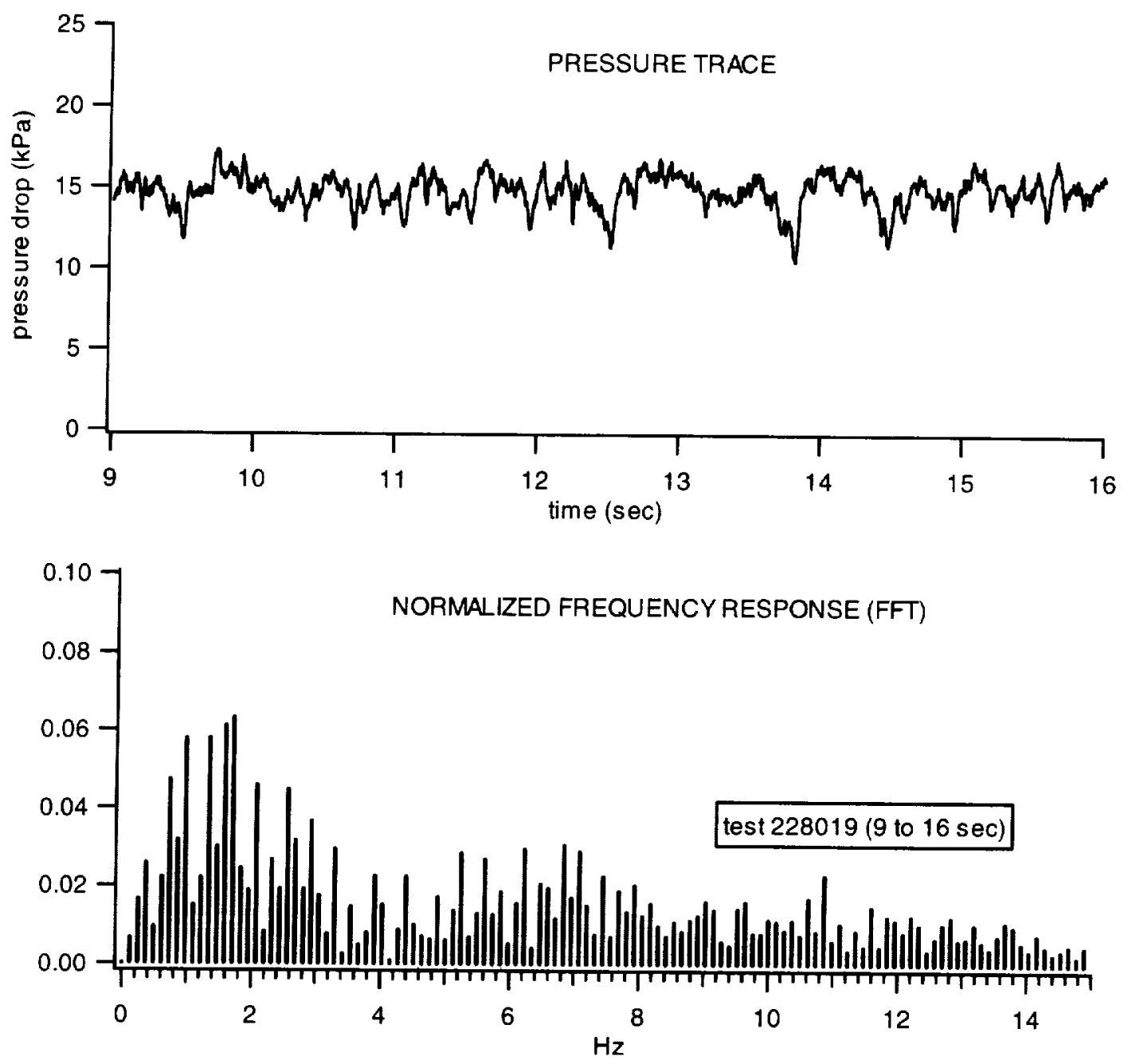

Figure 4.-Typical pulse flow.

Figure 5 shows the transition boundaries between these two regimes using Talmor's coordinates. The dashed line represents the transition in normal gravity and is in agreement with our $1-\mathrm{g}$ data. For clarity, we leave the $1-\mathrm{g}$ data off of the map. The solid line represents the flow regime transitions in $0-\mathrm{g}$. If the ratio of forces proposed by Talmor is correct, the plot should still hold after the absence of gravity is accounted for through the Froude number. Instead, pulse flow was observed at a much lower volumetric gas to liquid ratio than predicted. One possible reason for this shift in the flow regime transition may be due to the enhanced role of the capillary forces in determining the amplitude of the waves that exist on the liquid film surrounding the particles. In addition, the wetting of the particles by the liquid in $0-\mathrm{g}$ is different than in $1-\mathrm{g}$ since the gravitational draining force is not present in $0-\mathrm{g}$. We present some data in a later section which shows that for the same gas and liquid flow rates, the pulse amplitude is larger in $0-\mathrm{g}$ than in $1 . \mathrm{g}$.

\section{Pressure Drop and Liquid Holdup}

\section{Background}

Total pressure drop is an important design parameter in two-phase gas-liquid packed beds. It determines the operational power and is used as a correlating variable to estimate mass transfer rates (Gianetto ${ }^{10}$ et al.). Another important design parameter, related to pressure drop, is the liquid holdup in a column. Liquid holdup refers to the amount of liquid that is retained within the non-porous packing and is classified as static or dynamic. Static holdup is the easier of the two to determine experimentally and is directly related to the competing gravitational and surface tension forces. It is usually measured by flooding the column with a known amount of liquid and then allowing the column to drain. The difference is considered the static holdup. Charpentier $^{7}$ et al. first presented a correlation, which 


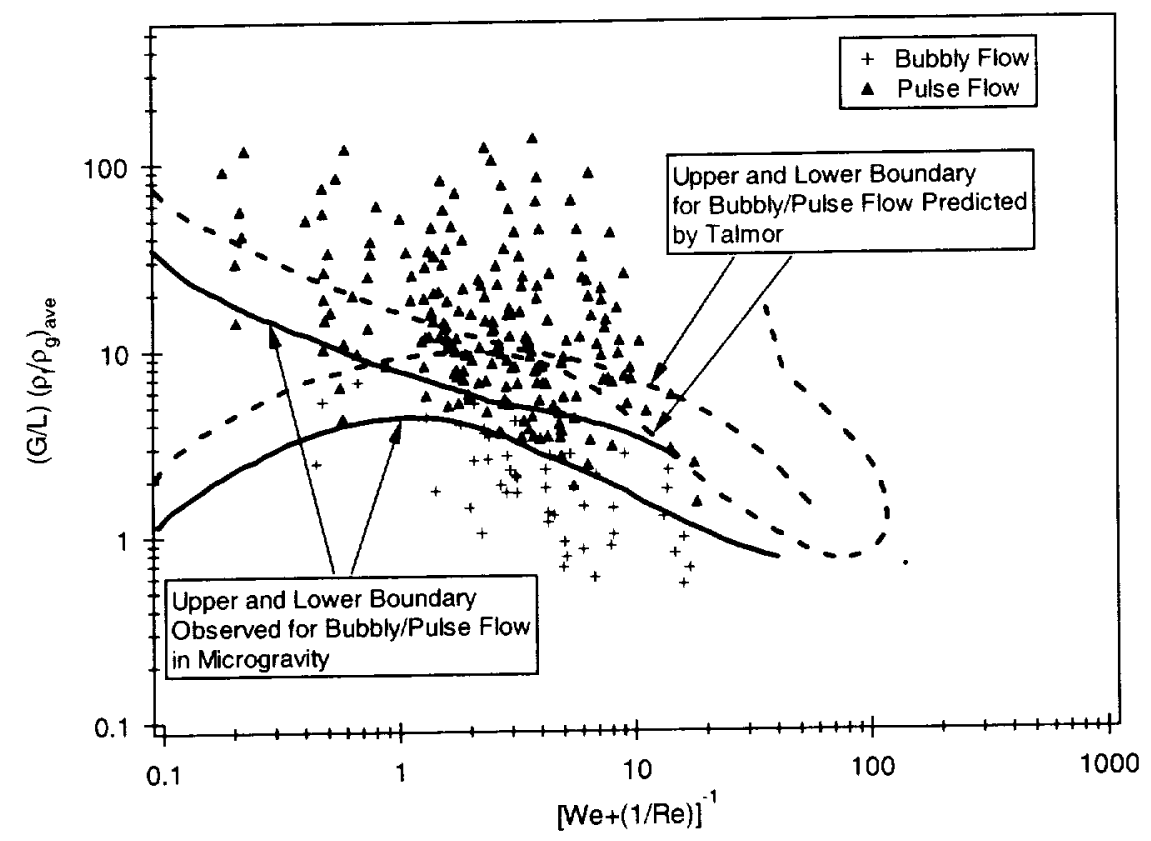

Figure 5.-Flow map in microgravity.

was improved on by Saez and Carbonell, " between the static holdup and the ratio of these forces using the Eotvos (or Bond) number.

$E o=\frac{\rho_{L} g D_{p}^{2}}{\sigma_{L}}$

In these correlations, the limiting value of static hold-up is $11 \%$ as Eo approaches zero. This in fact does not hold for the microgravity environment. In the absence of gravity, the flooded column does not drain and the static liquid holdup is $100 \%$.

Dynamic holdup is more difficult to determine accurately. Correlations between pressure drop and dimensionless groups such as the $\mathrm{Re}$ and We have been attempted with some success. Measurement techniques such as stopping the flow and measuring the amount drained before the flow becomes static are used as well as many attempts to directly measure the total liquid holdup during actual flow and then subtracting the static component. Obviously, it is difficult not to introduce significant experimental error.

There are two basic types of hydrodynamic models used to estimate pressure drop. One approach uses empirical correlations (Sato ${ }^{8}$ and Midoux ${ }^{12}$ et al.) the other uses a modified Ergun equation (Saez ${ }^{11}$ and Holub ${ }^{13}$ et al.).

\section{Comparison to Reduced Gravity}

In this section, we compare the effect of gravity on total pressure drop for both the bubbly and pulse flow regimes.

At low gas and liquid flow rates, figure 6 illustrates the pressure drop varies linearly with the liquid flow rate for both normal and reduced gravity. This is consistent with the well-known Darcy relationship

$-\nabla P=\frac{\mu}{K} u_{D}$

where $\mathrm{K}$ is the permeability of the packing and $u_{D}$ is the average filter (packing) velocity vector. The Darcy model gives a good correlation for single-phase liquid at low velocities. However, as the liquid velocity is reduced to a flow rate that would produce trickle flow in normal gravity, bubble flow is still observed in the reduced gravity case.

Another important observation is the slope of both curves in figure 6 is nearly the same. The difference is roughly equivalent to the liquid static head.

Figure 7 spans both the bubbly and pulse flow regimes with a constant liquid flow. In this plot, it can be seen that the pressure drop difference between $1-\mathrm{g}$ and $0-\mathrm{g}$ 


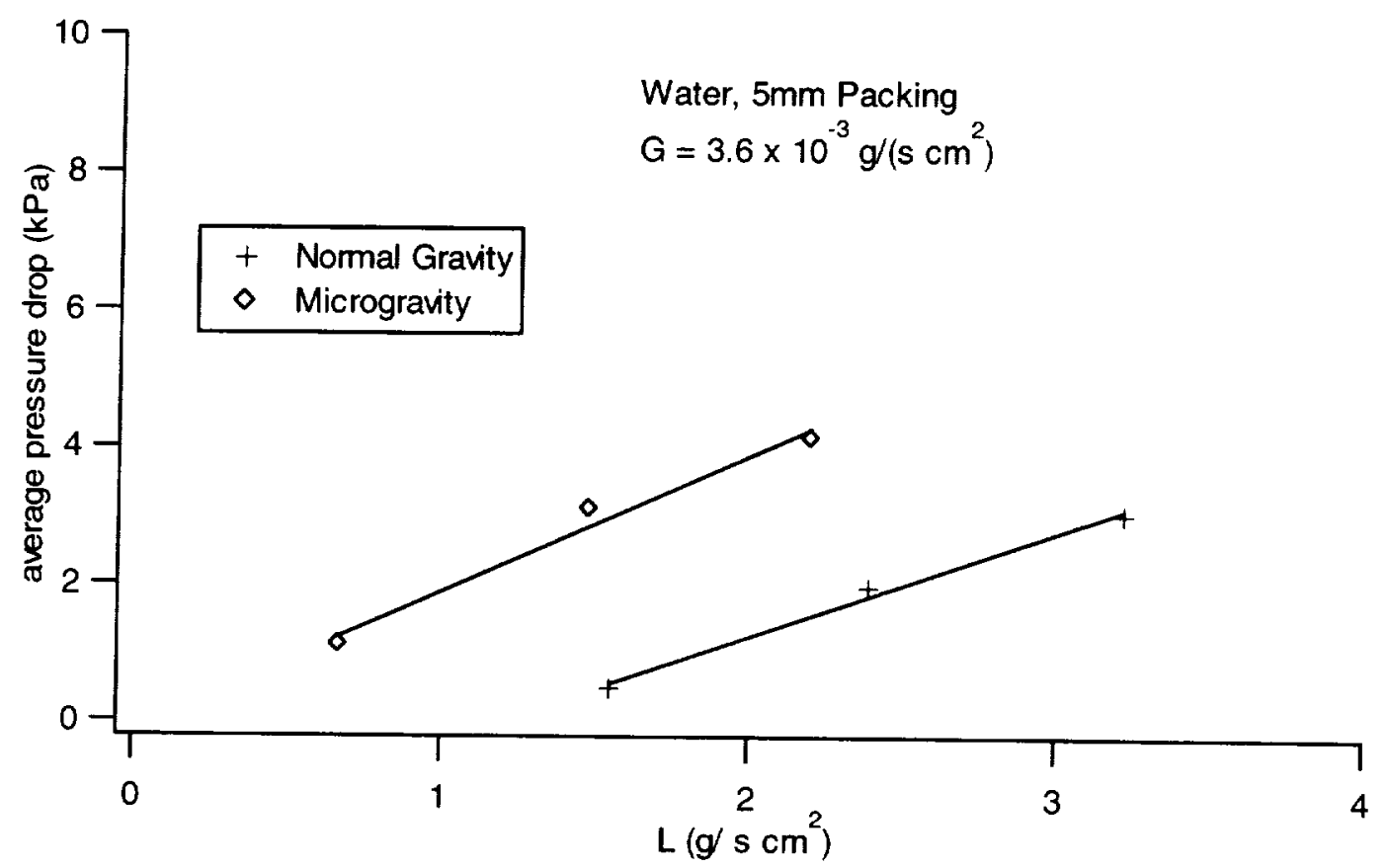

Figure 6.-Average pressure drop for bubbly flow.

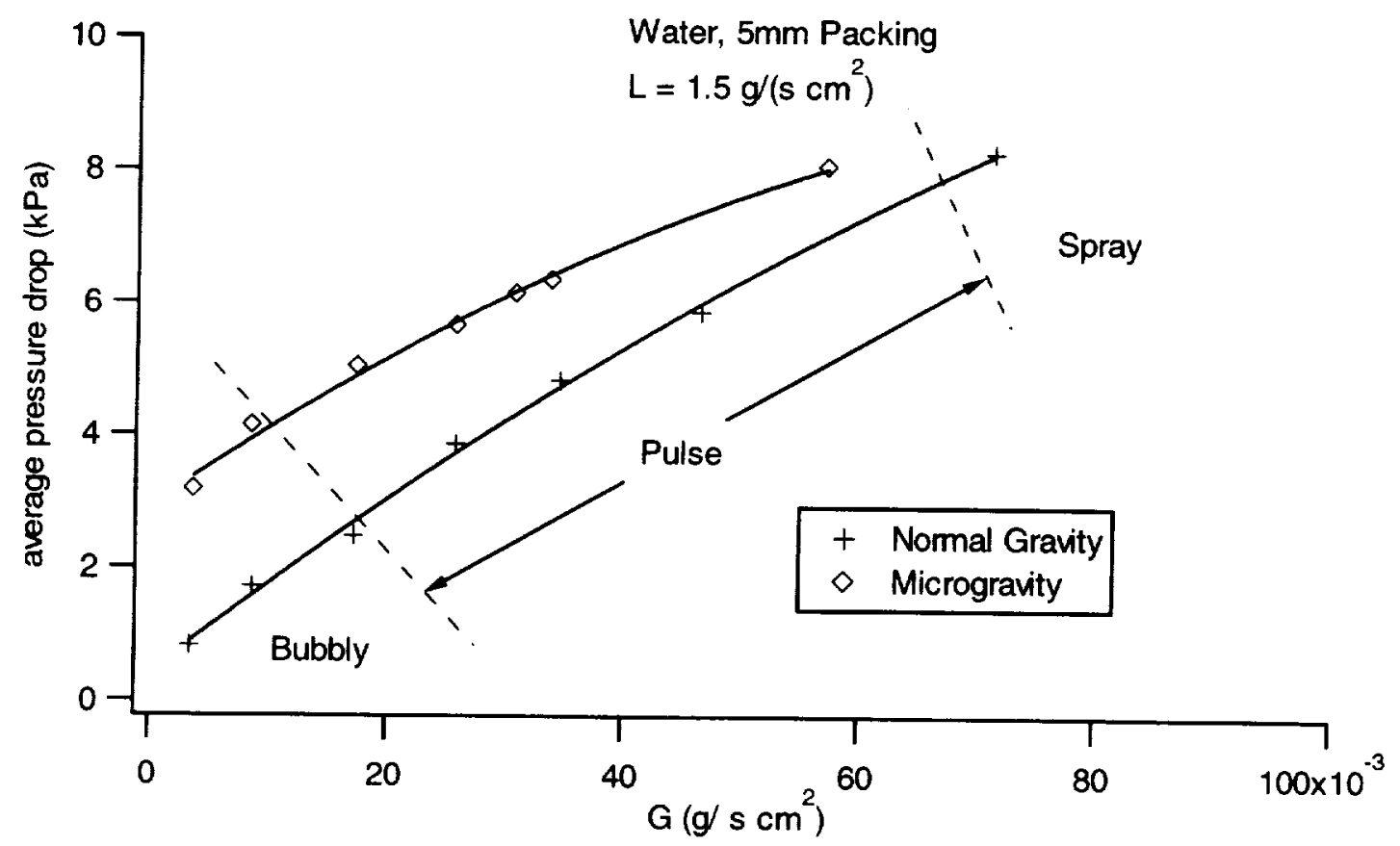

Figure 7.-Average pressure drop for pulse flow. 
$(1 \mathrm{psi}=6.89 \mathrm{kPa})$

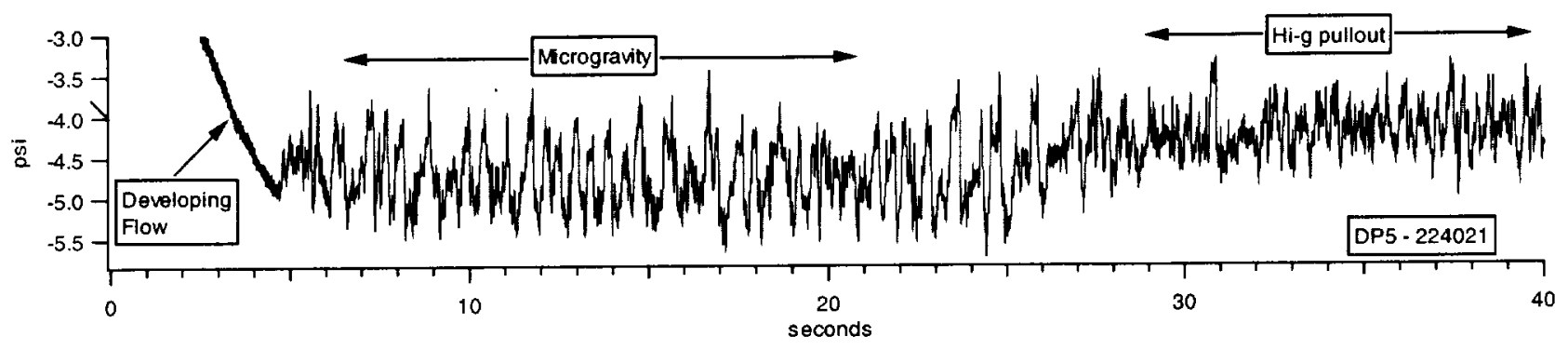

\begin{tabular}{|c|c|c|c|}
\hline & $\begin{array}{c}\text { Microgravity } \\
(10-18 \mathrm{~s})\end{array}$ & $\begin{array}{c}\text { High Gravity } \\
(32-40 \mathrm{~s})\end{array}$ & Difference \\
\hline Average Pressure Drop & $28.61 \mathrm{kPa}$ & $32.75 \mathrm{kPa}$ & $4.14 \mathrm{kPa}$ \\
\hline Pulse Amplitude & $15.31 \mathrm{kPa}$ & $11.65 \mathrm{kPa}$ & $3.66 \mathrm{kPa}$ \\
\hline
\end{tabular}

Figure 8.-Effect of gravity on pulse amplitude.

begins to decrease as the inertia forces begin to dominate the flow. If the data is extrapolated into the spray flow regime, the difference becomes negligible. Assuming the frictional pressure loss is the same for both gravity environments, the difference in pressure drop between the two is a direct measurement of the dynamic and static head on the column. From this, the dynamic liquid holdup can be determined.

\section{Pulse Characteristics}

The pulse amplitude is also affected by the relative strength of the gravitational forces. Figure 8 illustrates a typical pulse flow in which we continued to record the pressure trace beyond the microgravity segment of the aircraft trajectory. As the aircraft begins to pull out of the microgravity "dive", the experiments on board experience an increased downward acceleration (relative to the experiment) of about 1.8 times that of normal gravity.

From the pressure trace, it is clear that not only does the average pressure drop shift as we discussed above, but the pulse amplitude decreases with increasing downward acceleration. In this case, the amplitude decreases by $3.66 \mathrm{kPa}$.

This observation provides insight into the apparent shift of the flow regime transitions seen in the Talmor map. As shown earlier, pulse flow occurs at a much lower $\mathrm{G} / \mathrm{L}$ in the absence of gravity than predicted. This indicates that gravity has a stronger influence over the bubbly-pulse transition than previously thought.

\section{Conclusions}

We have presented in this work only some preliminary results of an ongoing study. Based on these results, two important conclusions can be drawn. First, the flow regimes and the transitions that exist are different in reduced gravity than in normal gravity. In reduced gravity, the trickle flow regime becomes either pulse or bubbly flow and the pulse flow regime is observed over a much wider range of conditions. Second, the total pressure drop in zero gravity is higher than normal gravity cocurrent downflow. If the frictional pressure drop is assumed to be nearly the same, or only slightly higher, the difference between these two can be used to estimate the dynamic liquid holdup in normal gravity cocurrent downflows. In addition, this study demonstrates the utility of reduced gravity experiments in the understanding of normal gravity multiphase flows. For example, by fixing the gas and liquid flow rates and varying only the gravity level (from $1-\mathrm{g}$ to $0-\mathrm{g}$ and $1.8 \mathrm{~g}$ ) we can estimate the influence of gravity on any common transition boundary, the true frictional pressure drop, and the dynamic liquid holdup in a given flow regime. This will be pursued in more detail in future work. 


\section{$\underline{\text { References }}$}

1. Talmor, E., "Two-Phase Downflow Through Catalyst Beds," AIChE J., vol. 23, no. 6, pp. 868-878 (1977).

2. Singh, B.S., "Workshop on Research for Space Exploration: Physical Sciences and Process Technology," NASA/CP-1998-207431, (1998).

3. Committee on Microgravity Research Space Studies Board, commission on Physical Sciences, Mathematics, and Applications National Research Council, "Microgravity Research in Support of Technologies for the Human Exploration and Development of Space and Planetary Bodies," National Academy Press ( 1998).

4. Holder, D.W., and Parker, D.S., "Volatile Removal Assembly Flight Experiment and KC-135 Packed Bed Experiment: Results and Lessons Learned," 30th International Conference on Environmental Systems, SAE\# 2000-01-2251 (2000).

5. Motil, B.J., Green, R.D., Nahra, H.K., and Sridhar, K.R., "Two-Phase Flow in Packed Columns and Generation of Bubble Suspensions for Chemical Processing in Space," 30th International Conference on Environmental Systems, SAE\# 2000-01-2239 (2000). NASATM-2000-210212.

6. Weekman, V.W., and Myers, J.E., "Fluid-Flow Characteristics of Concurrent Gas-Liquid Flow in Packed Beds," AIChE J., vol. 10, no. 6, pp. 951-957 (1964).
7. Charpentier, J.C.. and Favier, M., "Some Liquid Holdup Experimental Data in Trickle-Bed Reactors for Foaming and Nonfoaming Hydrocarbons," AIChE J., vol. 21, no. 6. pp. 1213-1218 (1975).

8. Sato, Y., Takahashi, F., and Hashiguchi, Y., "Flow Pattern and Pulsation Properties of Cocurrent GasLiquid Downflow in Packed Beds," J. Chem. Eng., Japan, vol. 6, no. 4, pp. 315-319 (1973).

9. Oshinowo, T., and Charles, M.E., "Vertical Two-Phase Flow, Part I, Flow Pattern Correlations," Can. J. Chem. Eng., vol. 52, pp. 25-35. (1974).

10. Gianetto, A., Baldi, G., Specchia, V., Sicardi, S., "Hydrodynamics and Solid-Liquid Contacting Effectiveness in Trickle-Bed Reactors," AIChE J., vol. 24, no. 6, pp. 1087-1104 (1978).

11. Saez, A.E., and Carbonell, R.G., "Hydrodynamic Parameters for Gas-Liquid Cocurrent Flow in Packed Beds," AIChE J., vol. 31, no. 1, pp. 52-62 (1985).

12. Midoux, N., Favier, M., and Charpentier, J.C., "Flow Pattern, Pressure Loss and Liquid Holdup Data in GasLiquid Downflow Packed Beds with Foaming and Nonfoaming Hydrocarbons." J. Chem. Eng., Japan, vol. 9, no. 5, pp. 350-356 (1976).

13. Holub, R.A., Dudukovic, M.P., Ramachandran, P.A., "Pressure Drop, Liquid Holdup, and Flow Regime Transition in Trickle Flow," AIChE J., vol. 39, no. 2, pp. 302-321 (1993) 
Davis Highway, Suite 1204. Arlington VA 20202.4302 and burden, to Washington Headquarters Services, Directorate for Intormation Operations and Reports, 1215 Jefferson

1.

\begin{tabular}{l|l|l} 
1. AGENCY USE ONLY (Leave blank) & 2. REPORT DATE & 3. REPORT TYPE AND DATES COVERED
\end{tabular}

4. TITLE AND SUBTITLE

February 2001

Technical Memorandum

Effects of Gravity on Cocurrent Two-Phase Gas-Liquid

Flows Through Packed Columns

6. AUTHOR(S)

WU-101-53-00-00

Brian J. Motil, Vemuri Balakotaiah, and Yasuhiro Kamotani

7. PERFORMING ORGANIZATION NAME(S) AND ADDRESS(ES)

National Aeronautics and Space Administration

John H. Glenn Research Center at Lewis Field

Cleveland, Ohio 44135-3191

5. FUNDING NUMBERS

8. PERforming ORgANIZATION

REPORT NUMBER

E- 12636

9. SPONSORING/MONITORING AGENCY NAME(S) AND ADDRESS(ES)

National Aeronautics and Space Administration

Washington, DC 20546-0001

10. SPONSORINGMONITORING AGENCY REPORT NUMBER

NASA TM-2001-210705

AIAA-2001-0767

11. SUPPLEMENTARY NOTES

Prepared for the 39th Aerospace Sciences Meeting and Exhibit sponsored by the American Institute of Aeronautics and Astronautics, Reno, Nevada, January 8-11, 2001. Brian J. Motil, NASA Glenn Research Center; Vemuri Balakotaiah University of Houston, 4800 Calhoun Road, Houston, Texas 77204; Yasuhiro Kamotani, Case Western Reserve University, 10900 Euclid Avenue, Cleveland, Ohio 44106. Responsible person, Brian J. Motil, organization code 6712, 216-433-6617.

12a. DISTRIBUTION/AVAILABILITY STATEMENT

Unclassified - Unlimited

Subject Category: 34

Distribution: Nonstandard

Available electronically at http://gltrs.grc,nasa.gov/GLTRS

This publication is available from the NASA Center for AeroSpace Information, 301-621-0390.

13. ABSTRACT (Maximum 200 words)

This work presents the experimental results of research on the influence of gravity on flow pattern transitions, pressure drop and flow characteristics for cocurrent gas-liquid two-phase flow through packed columns. The flow pattern transition data indicates that the pulse flow regime exists over a wider range of gas and liquid flow rates under reduced gravity conditions compared to normal gravity cocurrent down-flow. This is illustrated by comparing the flow regime transitions found in reduced gravity with the transitions predicted by Talmor. Next, the effect of gravity on the total pressure drop in a packed column is shown to depend on the flow regime. The difference is roughly equivalent to the liquid static head for bubbly flow but begins to decrease at the onset of pulse flow. As the spray flow regime is approached by increasing the gas to liquid ratio, the effect of gravity on pressure drop becomes negligible. Finally, gravity tends to suppress the amplitude of each pressure pulse. An example of this phenomenon is presented.

\section{SUBJECT TERMS}

Microgravity; Two-phase flow; Packed bed; Porous media

17. SECUAITY CLASSIFICATION OF REPORT

Unclassified
18. SECURITY CLASSIFICATION OF THIS PAGE

Unclassified

NSN 7540-01-280-5500

19. SECUAITY CLASSIFICATION OF ABSTRACT

Unclassified

\begin{tabular}{|c|c|}
\hline & $\begin{array}{c}\text { 15. NUMBER OF PAGES } \\
16\end{array}$ \\
\hline & $\begin{array}{r}\text { 16. PRICE CODE } \\
\mathrm{A03} \\
\end{array}$ \\
\hline $\begin{array}{l}\text { 19. SECUAITY CLASSIFICATION } \\
\text { OF ABSTRACT } \\
\text { Unclassified }\end{array}$ & 20. LIMITATION OF ABSTRACT \\
\hline
\end{tabular}

Standard Form 298 (Rev. 2-89)

Prescribed by ANSI Std. Z39-18 298-102 


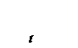

.

- 